\title{
Biocatalytic Routes to Lactone Monomers for Polymer Production
}

Hanan L. Messiha ${ }^{\dagger}$ Syed T. Ahmed, ${ }^{\ddagger}$ Vijaykumar Karuppiah, ${ }^{\dagger}$ Reynier Suardíaz, Gabriel A. Ascue Avalos, ${ }^{\dagger \dagger}$ Natalie Fey, ${ }^{\S}$ Stephen Yeates, ${ }^{\ddagger}$ Helen S. Toogood, ${ }^{\dagger *}$ Adrian J. Mulholland, ${ }^{\S}$ and Nigel S. Scrutton* ${ }^{* *}$

$\dagger$ BBSRC/EPSRC Manchester Synthetic Biology Research Centre for Fine and Specialty Chemicals (SYNBIOCHEM), and "School of Chemistry, Faculty of Science and Engineering, University of Manchester, 131 Princess Street, Manchester M1 7DN, U.K.

${ }^{\S}$ Centre for Computational Chemistry, School of Chemistry, University of Bristol, Cantock’s Close, Bristol BS8 1TS, U.K.

\section{CORRESPONDING AUTHOR}

*Professor Nigel S. Scrutton, Phone: +44 (0)1613065152. Fax: +44 (0)1613068918. E-mail: nigel.scrutton@manchester.ac.uk

\section{KEYWORDS}

Baeyer-Villiger monooxygenases (BVMOs), biocatalysis, crystallography, molecular dynamics simulations, DFT mechanistic study, biopolymers, ring-opening polymerization 


\section{ABSTRACT}

Monoterpenoids offer potential as bio-derived monomer feedstocks for high performance renewable polymers. We describe a biocatalytic route to lactone monomers menthide and dihydrocarvide employing Baeyer-Villiger monooxygenases (BVMOs) from Pseudomonas sp. HI-70 (CPDMO) and Rhodococcus sp. Phil $\left(\mathrm{CHMO}_{\mathrm{Phil}}\right)$ as an alternative to organic synthesis. The regio-selectivity of dihydrocarvide isomer formation was controlled by site-directed mutagenesis of three key active site residues in $\mathrm{CHMO}_{\mathrm{Phi1}}$. A combination of crystal structure determination, molecular dynamics simulations and mechanistic modeling using density functional theory (DFT) on a range of models provides insight into the origins of discrimination of wild type (WT) and a variant $\mathrm{CHMO}_{\text {Phi1 }}$ for producing different regio-isomers of the lactone product. Ring-opening polymerizations of the resultant lactones using mild metal-organic catalysts demonstrate their utility in polymer production. This semi-synthetic approach utilizing a biocatalytic step, non-petroleum feedstocks and mild polymerization catalysts, allows access to known and also to previously unreported and potentially novel lactone monomers and polymers.

\section{INTRODUCTION}

There is an increasing demand for the production of biodegradable plastics from renewable feedstocks due to both dwindling fossil fuel supplies and environmental concerns over the accumulation of petroleum-based non-recyclable plastic waste. ${ }^{1-3}$ This has led to the development biodegradable polymeric materials, including elastomers, plastics, hydrogels, flexible electronics, resins, engineering polymers and composites. ${ }^{4}$ Cyclic esters (lactones) have been widely used in the synthesis of biodegradable polymers, such as poly- $\varepsilon$-caprolactone (PCL) $)^{5}$ and polylactide (PLA) and related copolymers ${ }^{6-10}$, which are employed in a number of biomedical and pharmaceutical applications such as in drug delivery and tissue engineering ${ }^{11-14}$ and constitute the major component of many types of polyurethane biopolymers. ${ }^{15}$

Other bio-derived monomers of commercial interest are monoterpenoids, which generate polymers such as polymenthide (PM), polydihydrocarvide (PDC) and polycarvomenthide (PCM) and related 
ABA block copolymers of polylactide-polymenthide-polylactide triblocks (PLA-PM-PLA). These polymers have applications as thermoplastic elastomers and components of pressure sensitive adhesives. ${ }^{7}$ 15-17 Hybrid copolymers of PLA -PM-PLA triblocks are useful in pressure-sensitive adhesives formulations, as they have high-performing thermoplastic elastomer properties comparable to styrenic triblock copolymers. $^{7-9,17}$

Monomeric compounds can be derived from either natural sources, or as reported more recently via metabolic engineering of microorganisms to generate industrially viable biosynthetic routes. ${ }^{18}$ Currently the lactones menthide and dihydrocarvide are sourced primarily through chemical Baeyer-Villiger oxidation routes. ${ }^{19,20}$ Alternatively, biocatalytic routes employing flavin-dependent Baeyer-Villiger monooxygenases (BVMOs) ${ }^{21-23}$ could offer an attractive strategy to access these monomers (Scheme 1), with the advantage of increased stereo- and enantiomeric control of the product. ${ }^{24-27}$ This was first reported by Alphand and Furstoss and further investigated in more detail by the Mihovilovic group. ${ }^{28,}{ }^{29}$ The BVMO reaction is often regio-divergent, generating two lactone products, known as the 'normal' and 'abnormal' isomers (as in Scheme 1). ${ }^{29}$ Therefore, candidates from the BVMO family could be selected as biocatalysts based on their enantio- and regio-selectivity for the production of targeted lactone monomers for polymer synthesis. 
A)

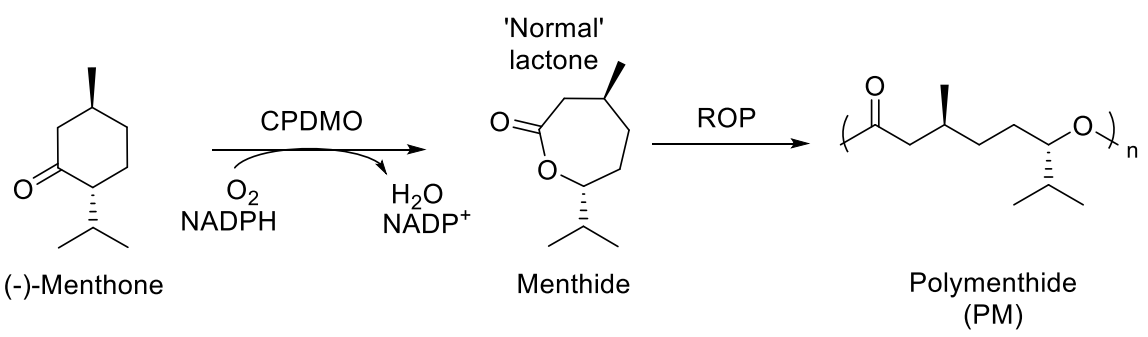

B)

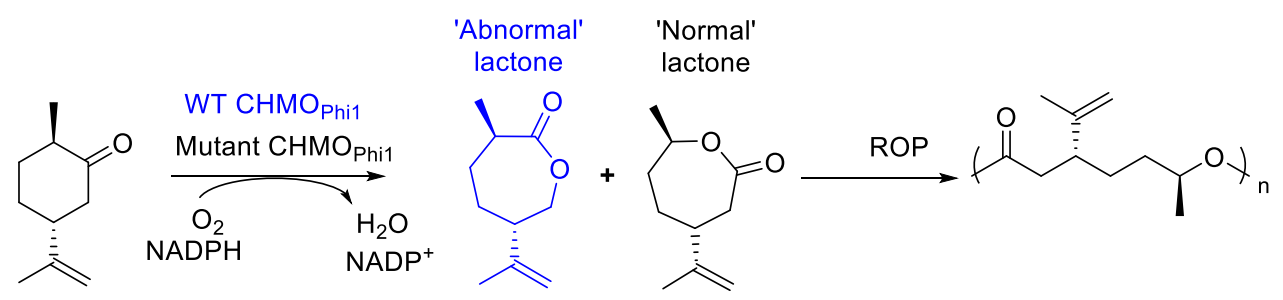

$(2 R, 5 R)-(+)$-Dihydrocarvone

(+)-Dihydrocarvide

Polydihydrocarvide (PDC)

C)<smiles>CC(C)=C1CCC(C)CC1=O</smiles>

(+)-Pulegone

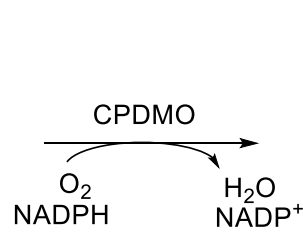

Lactone of pulegone

\section{'Normal'}

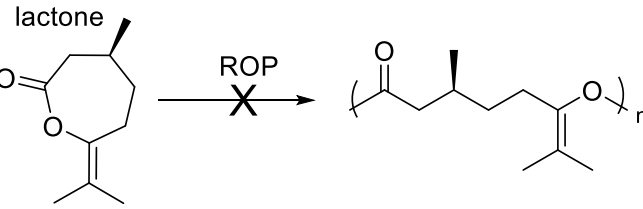

Scheme 1. Semisynthetic polymer production using lactone monomers.

Semisynthetic polymer production via BVMO-catalyzed lactone production coupled with ROP oxidation using $\mathrm{Mg}(\mathrm{BHT})_{2}(\mathrm{THF})_{2}$ and benzyl alcohol. $\left.{ }^{30} \mathrm{~A}\right)$ Polymenthide, B) Polydihydrocarvide. The abnormal lactone of $(2 R, 5 R)$-(+)-dihydrocarvone is (3S,6R)-3-methyl-6-(prop-1-en-2-yl)oxepan-2-one. C) The BVMO reaction with (+)-pulegone. The normal lactone of $(+)$-pulegone is $(R)$-4-methyl-7-(propan-2ylidene)oxepan-2-one. The ROP of the lactone of $(+)$-pulegone was unsuccessful.

Ring-opening polymerization (ROP) reactions of lactone monomers are a common strategy to access polymers such as PM and PDC and similar polymers such as PCL and $\beta$-pinene. 7, 15, 19, 20, 31 The use of metal catalysts for the polymerization of $\varepsilon$-caprolactone, menthide, dihydrocarvide and carvomenthide is well established. ${ }^{32-34}$ Alternatively, enzymatic approaches employing lipase enzymes have been reported for low molecular weight polylactide production. ${ }^{35,36}$

This report describes an alternative route to lactone-based biopolymers by employing a biocatalytic lactone production step using BVMOs with ROP using mild metal-organic catalysts. This approach utilizes bio-derived monoterpenoid starting materials to generate lactone monomers using the 
BVMO enzymes cyclopentadecanone monooxygenase (CPDMO) from Pseudomonas sp. HI-70 37 and cyclohexanone monooxygenase from Rhodococcus sp. Phil $\left(\mathrm{CHMO}_{\mathrm{Phil}}\right){ }^{38}$ To enable the production of the 'normal' lactone from (+)-dihydrocarvone, we performed site-directed mutagenesis of $\mathrm{CHMO}_{\mathrm{Phil}}$, and determined the crystal structures of the wild type (WT) and variant enzymes. A combination of structural analyses, molecular dynamics and computational mechanistic studies gave insights into the mechanisms that drive the formation of abnormal and normal lactone from (+)-dihydrocarvone. Finally, ROP reactions using a milder metal-organic catalyst than the ones utilized in the current polymerization process enabled the generation of polymers that were characterized and analyzed. Our method provides an alternative approach to access lactone monomers converting low-value renewable resources into value-added polymers.

\section{MATERIALS AND METHODS}

CHMO gene syntheses and mutagenesis. The genes encoding CPDMO from Pseudomonas sp. HI-70 (UniProtKB: T2HVF7) and $\mathrm{CHMO}_{\text {Phi1 }}$ from Rhodococcus sp. Phil (UniProtKB: Q84H73) were synthesized by GenScript (USA), employing codon optimization for increased E. coli expression. CPDMO was sub cloned into pET15b, incorporating an N-terminal His 6 -tag and $\mathrm{CHMO}_{\text {Phil }}$ into pET21b with a C-terminal His 6 -tag. The $\mathrm{CHMO}_{\text {Phi1 }}$ triple variant F249A, F280A, F435A (variant thereafter) was generated by QuikChange site-directed mutagenesis (Agilent) according to the manufacturer's protocols. Primer sequences used for the construction of the variant are shown in Table S1, Supporting Information). CPDMO and both $\mathrm{CHMO}_{\text {Phi1 }}$ (WT and variant) constructs were transformed into E. coli strains BL21(DE3) and C41(DE3), respectively, for protein overexpression.

The BVMOs were purified from the cell pellets using Ni-NTA affinity chromatography according to the manufacturers protocols (Qiagen), followed by gel filtration for crystallography studies. Protein concentrations were determined by either UV-Visible spectroscopy $\left(\varepsilon_{450 \mathrm{~nm}}=11,300 \mathrm{M}^{-1} \mathrm{~cm}^{-}\right.$ 
${ }^{1}$ for flavins) or the Bio-Rad protein assay kit. Typical cell expression yields, purities and UV/Vis spectrum of each BVMO can be found in Table S2 and Figures S1-S2, respectively.

Self-sufficient biocatalyst production. Each BVMO was fused to the C-terminus of the cofactor regenerating enzyme (CRE) phosphite dehydrogenase from Pseudomonas stutzeri (PTDH; thermostable variant 18 -ptxD) ${ }^{39-41}$ via a six amino acid linker (SRSAAG) as described previously. ${ }^{41}$, ${ }^{42}$ Constructs were generated in pET15b, which positioned the $\mathrm{His}_{6}$-tag at the N-terminus of PTDH. Each CRE-BVMO was transformed into E. coli strain BL21(DE3) for protein overexpression (see Supporting Information for details).

Analytical scale biotransformations. Biotransformations $(1 \mathrm{~mL})$ with either purified BVMOs $(2$ $\mu \mathrm{M})$ or cell-free extracts, CFEs $(50 \mu \mathrm{L})$ were performed in buffer $(50 \mathrm{mM}$ Tris $\mathrm{pH} 7.0)$ containing substrate ( $5 \mathrm{mM}$ unless otherwise stated) and a cofactor recycling system (15 $\mu \mathrm{M} \mathrm{NADP}^{+}, 15 \mathrm{mM}$ glucose and $10 \mathrm{U}$ glucose dehydrogenase (GDH) from Pseudomonas sp.). Reactions with CREBVMOs contained sodium phosphite $(100 \mathrm{mM})$ in the place of the cofactor recycling system. Reactions were agitated $(140 \mathrm{rpm})$ for $12 \mathrm{~h}$ at $28^{\circ} \mathrm{C}$, and terminated by extraction with ethyl acetate $(1 \mathrm{~mL})$ containing an internal standard $(0.1 \%$ sec-butyl-benzene $)$. The extracts were dried using anhydrous magnesium sulfate, and analysed by GC/MS (see Supporting Information for further details). Quantitative analysis was carried out by a comparison of product peak areas to standards of known concentrations.

Preparative scale reactions for lactone generation. Biotransformations (500 mL) were carried out with CRE-BVMOs (CFEs; $25 \mathrm{~mL})$ in buffer (50 mM Tris $\mathrm{pH} 7.0)$ containing substrate $(5 \mathrm{mM})$ and sodium phosphite $(100 \mathrm{mM})$. The reactions were agitated $(140 \mathrm{rpm})$ at $28^{\circ} \mathrm{C}$ for $12 \mathrm{~h}$ followed by multiple ethyl acetate extractions ( $20 \times 25 \mathrm{~mL}$ fractions). The pooled extracts were dried using anhydrous magnesium sulfate and concentrated in vacuo to give the crude lactone monomers as pale yellow oils. The crude samples were further purified by flash column chromatography (hexane:ethyl acetate, 9:1) to afford the pure lactone monomers as clear oils (46-14.5\% isolated 
yield of high purity product $>99.0 \%$ ). The identity and purity of the lactone monomers produced were assessed by GC/MS and NMR $\left({ }^{1} \mathrm{H}\right.$ NMR and ${ }^{13} \mathrm{C}$ NMR) analysis (Figures S3-S14).

Lactone polymerization. The ROP of lactone monomers was performed using the metal-organic catalyst magnesium 2,6-di-tert-butyl-4-methylphenoxide $\left[\mathrm{Mg}(\mathrm{BHT})_{2}(\mathrm{THF})_{2}\right]$ at $80{ }^{\circ} \mathrm{C}$ as described previously, but conducting the reaction in $2 \mathrm{~mL} .{ }^{30}$ Due to the oxygen and moisture sensitivity of the reaction, lactones were lyophilised, followed by an additional drying step over activated silica for 48 h. ROP of the commercially available $\varepsilon$-caprolactone was also performed to produce PCL. Polymerization reactions were performed anaerobically, keeping a ratio of 50:1:1 for the monomers:catalyst:initiator (Table S3). The polymerization process was carried out in an oxygenand moisture free environment (both $<0.5 \mathrm{ppm}$ ). Polymer PM was purified as reported, ${ }^{30}$ while PCL was purified by precipitation into hexane followed by a drying step. Purification of PDC was performed in a hexane/ethyl acetate (9:1) mixture, recovered from the immiscible layer and dried. Gel permeation chromatography (GPC) and ${ }^{1} \mathrm{H}$ NMR spectroscopy was used to detect polymer formation.

Protein crystallization and structure solution. Both $\mathrm{CHMO}_{\mathrm{Phi}} \mathrm{WT}$ and variant proteins (8-10 $\mathrm{mg} / \mathrm{mL})$ were subjected to crystallization as apoproteins and in the presence of NADP ${ }^{+}(2 \mathrm{mM})$. Crystallization drops (200 $\mathrm{nL}$ each of protein and reservoir solution) were generated using the Mosquito robot (TTP Labtech) with five screens (JCSG+, PACT Premier, SG1, Morpheus I and Morpheus II from Molecular Dimensions Limited) and incubated at $4^{\circ} \mathrm{C}$ for 1 week. The WT $\mathrm{CHMO}_{\text {Phil }}$ crystallized in SG1 B5 condition (0.2 M calcium chloride and 20\% w/v PEG 3350) and the variant crystallized in PACT Premier F2 condition $(0.2 \mathrm{M}$ sodium bromide, $0.1 \mathrm{M}$ Bis-Tris propane pH 6.5 and 20\% w/v PEG 3350). Plate-like crystals were cryo-protected with mother liquor containing $20 \%$ glycerol and flash cooled in liquid $\mathrm{N}_{2}$.

X-ray data were collected at Diamond Light Source beamlines I03 and I04-1. Data were processed using xia2 $2^{43}$ implementing $\mathrm{XDS}^{44}$ and XSCALE. The WT and the variant structures of $\mathrm{CHMO}_{\text {Phi1 }}$ were solved by molecular replacement using $\mathrm{CHMO}_{\text {closed }}$ structure (PDB 3GWD) from 
Rhodococcus sp. HI-31 as the search model in Phaser. ${ }^{45}$ The models were built using the AutoBuild $^{46}$ wizard in Phenix. ${ }^{47}$ The models were completed using iterative rounds of model building using $\operatorname{Coot}^{48}$ and refinement using phenix.refine. ${ }^{49}$ The structures were analyzed using PDB_REDO ${ }^{50}$ server and validated using Molprobity. ${ }^{51}$ The X-ray data collection and refinement statistics are provided in Table 1. The atomic coordinates and structure factors have been deposited in the Protein Data Bank with accession codes 6ER9 and 6ERA.

Table 1. X-ray data collection and refinement statistics

\begin{tabular}{|c|c|c|}
\hline & WT CHMO $_{\text {Phi1 }}$ & Variant CHMO $_{\text {Phi1 }}$ \\
\hline Space group & $\mathrm{P} 12_{1} 1$ & P 121 \\
\hline Unit cell dimensions & $\begin{array}{l}a=54.08 \AA, b=64.44 \AA, c=186.22 \AA ; \\
\alpha=90^{\circ}, \beta=96.02^{\circ}, \gamma=90^{\circ}\end{array}$ & $\begin{array}{l}a=53.86 \AA, b=64.94 \AA, \\
c=187.59 \AA ; \alpha=90^{\circ}, \\
\beta=97.03^{\circ}, \gamma=90^{\circ}\end{array}$ \\
\hline X-ray source & DLS I03 & DLS I04-1 \\
\hline Wavelength $(\AA)$ & 0.97625 & 0.92819 \\
\hline Resolution range $(\AA)$ & $92.60-2.37(2.43-2.37)^{\mathrm{a}}$ & $62.06-2.49(2.53-2.49)^{\mathrm{a}}$ \\
\hline Completeness $(\%)$ & $98.8(99.6)$ & $99.8(99.9)$ \\
\hline Multiplicity & $3.2(3.1)$ & $4.1(4.1)$ \\
\hline$I / \sigma I$ & $7.9(1.3)$ & $9.9(1.1)$ \\
\hline $\mathrm{R}_{\text {merge }}$ & $0.085(0.727)$ & $0.082(0.995)$ \\
\hline $\mathrm{R}_{\text {meas }}$ & $0.127(1.10)$ & $0.094(1.093)$ \\
\hline $\mathrm{R}_{\text {pim }}$ & $0.070(0.614)$ & $0.045(0.525)$ \\
\hline$C C_{1 / 2}$ & $0.993(0.523)$ & $0.998(0.587)$ \\
\hline Total observations & $163400(11814)$ & $187824(9073)$ \\
\hline Total unique & $51521(3797)$ & $45368(2228)$ \\
\hline \multicolumn{3}{|l|}{ Refinement } \\
\hline R-work & 0.199 & 0.214 \\
\hline R-free & 0.245 & 0.260 \\
\hline RMS (bonds) & 0.006 & 0.005 \\
\hline RMS (angles) & 0.81 & 0.72 \\
\hline \multicolumn{3}{|l|}{ Average B-factor $\left(\AA^{2}\right)$} \\
\hline Average & 72.40 & 84.10 \\
\hline FAD & 46.37 & 80.94 \\
\hline $\mathrm{NADP}^{+}$ & 59.92 & 101.58 \\
\hline \multicolumn{3}{|l|}{ Ramachandran plot } \\
\hline Favored & 95.93 & 94.12 \\
\hline Allowed & 3.97 & 5.78 \\
\hline Outliers & 0.1 & 0.10 \\
\hline
\end{tabular}

${ }^{a}$ Values in the parentheses refer to the outer resolution shell.

Computational modeling. Molecular dynamics simulations were performed on WT and variant $\mathrm{CHMO}_{\text {Phil }}$ in the presence of FAD and NADPH, and also in the presence of the reaction 
intermediate. Details of the simulations performed are described in the Supporting Information document. Mechanistic studies used "cluster models" $" 52,53$ and density functional theory (mPW91 + modified B95 (PWB6K) functional) to identify the key structural elements controlling the reactivity and selectivity of these biocatalysts. Details of these calculations and additional calculated data are summarized in the Supporting Information.

\section{RESULTS AND DISCUSSION}

BVMO selection and production. Previous studies showed that CPDMO oxidizes (-)-menthone to produce menthide, ${ }^{37}$ and variant CHMOs from Arthrobacter sp. BP2 $\left(\mathrm{CHMO}_{\mathrm{Ar}}\right)$ and Acinetobacter calcoaceticus $\left(\mathrm{CHMO}_{\mathrm{Ac}}\right)$ generate dihydrocarvide (the normal lactone) from $(+)$-dihydrocarvone. ${ }^{54}$ A screen of in house BVMOs showed that $\mathrm{CHMO}_{\mathrm{Ar}}$ and $\mathrm{CHMO}_{\mathrm{Ac}}$ expressed poorly (results not shown), while $\mathrm{CHMO}_{\mathrm{Phi}}$ was highly expressed and could oxidize $(2 R, 5 R)-(+)$-dihydrocarvone isomer (as shown in this study). Therefore CPDMO and $\mathrm{CHMO}_{\mathrm{Phi} 1}$ were chosen for further study, and were expressed in E. coli, purified and assessed for flavin content (UV/Vis spectroscopy; Figures S1-S2; Table S2).

Given that BVMOs are NADPH-dependent, a cofactor recycling system is required to minimize the prohibitive costs of nicotinamide cofactor addition. ${ }^{55}$ Prior studies with six BVMOs showed that the fusion of the C-terminus of a thermostable variant of phosphite dehydrogenase from Pseudomonas stutzeri (18-ptxD PTDH) ${ }^{40}$ to the N-terminus of the monooxygenase via a six amino acid linker (SRSAAG) generated self-sufficient enzymes (CRE-BVMO). Cofactor regeneration during biotransformations was achieved via the action of PTDH with sodium phosphite. ${ }^{41,42}$ We used this strategy to generate CRE-CPDMO and CRE-CHMO ${ }_{\text {Phi1 }}$ (WT and variant), all were expressed in $E$. coli, purified and assessed for flavin content (UV/Vis spectroscopy; Figures S1-S2; Table S2). This enabled comparative biotransformations to be performed in the presence of phosphite/NADP ${ }^{+}$ (CRE-BVMO) or an exogenously added cofactor recycling system (glucose/GDH/NADP ${ }^{+}$; BVMO). 
Biotransformations of CPDMO. Biotransformations (1 mL) of purified CPDMO with (-)menthone $(5 \mathrm{mM})$ showed a near complete conversion to menthide, with product identification later confirmed by GC/MS, ${ }^{1} \mathrm{H}$ and ${ }^{13} \mathrm{C}$ NMR (Figure S3-S4 and S11, respectively). Similarly, reactions with CFEs of CPDMO or CRE-CPDMO yielded $93.5 \%$ menthide, with a minor $(6.5 \%)$ secondary peak detected (Figure S5). Subsequent analysis showed this minor product had identical mass fragmentation patterns to menthide, suggesting it may be a different isomer (Figure S6).

To assess the scale-up potential of these reactions, reactions with CRE-CPDMO extracts were performed with variable (-)-menthone concentrations $(5-50 \mathrm{mM})$. Analytical scale reactions with substrate concentrations above $10 \mathrm{mM}$ led to a significant decrease in product yield (Table 2).

Larger-scale reactions were performed with CRE-CPDMO extracts $(500 \mathrm{~mL})$, resulting in lower menthide yields of $73 \%$ and the detection of the substrate isomer isomenthone (Figure S7). The generation of isomenthone with CRE-CPDMO extracts, but not purified protein is not surprising as prior studies with CFEs of E. coli showed the isomerization of menthone, and isomenthone that is likely to proceed via a classical glutamate racemase-type mechanism. ${ }^{56}$

Therefore, subsequent preparative-scale biotransformation reactions were performed with $5 \mathrm{mM}$ of (-)-menthone to both optimize menthide yield and purity.

Table 2. Effect of substrate concentration on menthide yields with CRE-CPDMO.

\begin{tabular}{llc}
\hline$(-)$-Menthone $(\mathrm{mM})$ & Conversion $(\%)^{\mathrm{a}}$ & Menthide yield $(\%)^{\mathrm{b}}$ \\
\hline 5 & $\sim 100$ & 91.4 \\
10 & $\sim 100$ & 92.2 \\
25 & 61.8 & 70.7 \\
50 & 40.5 & 66.4 \\
\hline
\end{tabular}

Reactions $(1 \mathrm{~mL})$ were performed in buffer $(100 \mathrm{mM}$ sodium phosphate, $\mathrm{pH} 7.0)$ containing (-)-menthone (5-50 mM) and CRE-CPDMO CFEs at $28{ }^{\circ} \mathrm{C}$ for $24 \mathrm{~h}$. Reaction products were extracted in ethyl acetate containing $0.1 \%$ sec-butyl-benzene and analysed by GC/MS using a DBWax column. ${ }^{a_{0}} \%$ of $(-)$-menthone converted to product $/ \mathrm{s}$. ${ }^{b_{0}} \%$ of menthide in the product/s. 
Biotransformations of CHMO $_{\text {Phil }}$. GC/MS analysis of biotransformations of purified WT

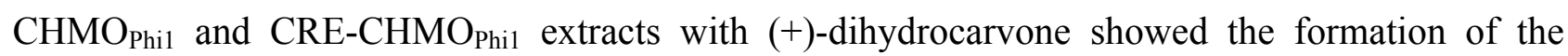
'abnormal' lactone (3S,6R)-3-methyl-6-(prop-1-en-2-yl)oxepan-2-one); Scheme 1, Figures S9a, S10a. Product identification was confirmed by ${ }^{1} \mathrm{H}$ and ${ }^{13} \mathrm{C}$ NMR using lactone purified from larger scale reactions (Figure S12). However, PDC polymers require the 'normal lactone' dihydrocarvide monomer, so the regio-selectivity of $\mathrm{CHMO}_{\text {Phil }}$ needed to be altered to enable the desired product to be formed.

Prior mutagenesis studies of $\mathrm{CHMO}_{\mathrm{Ar}}$ and $\mathrm{CHMO}_{\mathrm{Ac}}$ showed that a substrate regio-selectivity change could be achieved by mutating three active site amino acids (F299A/F330A/F485A; $\mathrm{CHMO}_{\mathrm{Ar}}$ numbering). ${ }^{54,57}$ Homologous mutations in both enzymes led to a complete switch from producing the 'abnormal' to 'normal' lactone from (+)-dihydrocarvone. ${ }^{54}$ An amino acid sequence alignment of $\mathrm{CHMO}_{\text {Phi1 }}$ with $\mathrm{CHMO}_{\mathrm{Ar}}$ and $\mathrm{CHMO}_{\mathrm{Ac}}$ showed moderate homology $(55 \%$; results not shown), enabling the 3 targeted phenylalanine residues to be identified (F249, F280 and F435). The homologous variant (F249A, F280A and F435A) was generated for both CHMO $_{\text {Phil }}$ and CRE$\mathrm{CHMO}_{\mathrm{Phi1}}$. The variant was expressed, purified (UV/Vis spectroscopy; Figures S1-S2; Table S2) and tested for activity with (+)-dihydrocarvone.

Biotransformations of variant $\mathrm{CHMO}_{\text {Phil }}$ (both purified protein and CFEs) showed that the regioselectivity of the enzyme had successfully switched to forming the 'normal' lactone dihydrocarvide as the major product (Figure S9b, S10b). Product identification was confirmed by ${ }^{1} \mathrm{H}$ and ${ }^{13} \mathrm{C}$ NMR using lactone purified from larger scale reactions (Figure S13). (+)-dihydrocarvone is commercially available as a mixture of two isomers, the $n$-isomer $(2 R, 5 R)$ and the $i s o$-isomer $(2 R, 5 S)$ at around 77:20 ratio (Figure S8a). Interestingly, reactions of purified WT and variant $\mathrm{CHMO}_{\mathrm{Phi}}$ with the commercially available $(+)$-dihydrocarvone showed conversion of only the $(2 R, 5 R)$-isomer $(>99 \%$; Figure S9a, S9b), yet both isomers appeared to be consumed in reactions containing CFEs ( $>99 \%$, Figure S10). This is likely due to the activity of a native E. coli enzyme capable of reacting with the $(2 R, 5 S)$ isomer of $(+)$-dihydrocarvone. 
Preparative-scale lactone production. Larger-scale reactions $(2 \times 500 \mathrm{~mL} ; 5 \mathrm{mM}$ substrate $)$ were performed to generate both menthide and dihydrocarvide using CFEs of CRE-CPDMO and the CRE-CHMO ${ }_{\text {Phill }}$ variant, respectively. Each product was solvent extracted and purified to generate lactone oils (>99\% purity) with yields of $403 \mathrm{mg}$ of menthide (47\%) and $211 \mathrm{mg}$ of dihydrocarvide (33\%). The identity and purity of the lactones were confirmed by ${ }^{1} \mathrm{H}$ and ${ }^{13} \mathrm{C}$ NMR analysis (Figure S11 and S13).

As further proof of principle, the same methodology was applied to generate the lactone of $(+)$ pulegone ((R)-4-methyl-7-(propan-2-ylidene)oxepan-2-one), Scheme 2 and the abnormal lactone of (+)-dihydrocarvone, Scheme 1B using CRE-CPDMO and WT CHMO Phill, respectively (Supporting Information for more details and NMR data). The products were purified $(>99 \%)$ and the structures confirmed by ${ }^{1} \mathrm{H}$ and ${ }^{13} \mathrm{C}$ NMR analysis (Figure S12 and S14). The yield of lactone of (+)-pulegone and the abnormal lactone of (+)-dihydrocarvone were $121.4 \mathrm{mg}(29.4 \%)$ and 190.1 mg (14.4\%), respectively. Optimization to improve both the product yield and recovery after purification would be needed to increase the applicability of biosynthetic lactone production on an industrial scale.

Ring opening polymerization of lactone monomers. We have demonstrated the efficient biosynthesis of a range of monoterpenoid lactone monomers on a preparative scale. The next stage is to implement a more environmentally friendly ROP to further improve the production of existing and novel bio-based polymers. By controlling the molecular weight and composition of the polymers, their properties can be tailored for use in diverse applications. ${ }^{58}$ Previous studies have described the synthesis and characterisation of polymers derived from menthide ${ }^{19,} 59$ and dihydrocarvide, $^{20}$ including ROP reactions using the milder $\left[\mathrm{Mg}(\mathrm{BHT})_{2}(\mathrm{THF})_{2}\right]$ catalyst with menthide ${ }^{30}$ and $\varepsilon$-caprolactone. ${ }^{60}$

The BVMO-derived lactones menthide, dihydrocarvide and pulegone lactone were subjected to ROP reactions using $\left[\mathrm{Mg}(\mathrm{BHT})_{2}(\mathrm{THF})_{2}\right]$ catalyst. $^{30}$ As a control, we also performed comparative 
ROP with commercially available $\varepsilon$-caprolactone, to enable a comparison of polymer sizes with previously published values. Each polymer was purified, and analysed by both ${ }^{1} \mathrm{H}$ NMR spectroscopy (Figure S15-S16) and triple detection GPC (Figure S17-S18), to confirm the polymeric nature and molecular distribution of the products (Table 3). There was no evidence of polymer formation with the pulegone lactone (see Supporting Information for discussion).

Table 3. GPC quantitative parameters of each polymer using OMISEC ${ }^{\mathrm{TM}}$ Multi Detection GPC analysis.

\begin{tabular}{llllll}
\hline Polymer & $\mathrm{M}_{\mathrm{n}}(k \mathrm{Da})$ & $\mathrm{M}_{\mathrm{w}}(k \mathrm{Da})$ & $\mathrm{Ð}_{\mathrm{M}}$ & $\mathrm{IV}(\mathrm{dL} / \mathrm{g})$ & $\mathrm{Rh}(\mathrm{nm})$ \\
\hline Polymenthide (PM) & 6.55 & 7.98 & 1.22 & 0.14 & 2.57 \\
Polydihydrocarvide (PDC) & 6.11 & 7.42 & 1.21 & 0.11 & 2.29 \\
PolyE--caprolactone (PCL) & 6.58 & 11.73 & 1.79 & 0.24 & 3.39 \\
\hline
\end{tabular}

$\mathrm{M}_{\mathrm{w}}=$ weight average molecular weight; $\mathrm{M}_{\mathrm{n}}=$ number average molecular weight; $\mathrm{Ð}_{\mathrm{M}}=$ sample dispersity; IV = intrinsic viscosity; Rh = hydrodynamic radius. The GPC was coupled with refractive index (RI), Right-Angle Light Scattering (RALS), Low-Angle Light Scattering (LALS) and viscometer detection. Samples were prepared in THF (3 mg/mL of solid polymer or $20 \mu \mathrm{L}$ of liquid polymer $/ \mathrm{mL}$ ) and $50 \mu \mathrm{L}$ injections of samples were separated isocratically on a set of standard ViscoGel columns. The columns and detectors were maintained at $35{ }^{\circ} \mathrm{C}$. The detectors recorded the elution of the samples from the columns and the analysis was performed using the OMNISEC ${ }^{\mathrm{TM}}$ V10.20 software. The data presented are the average of three measurements. The $\mathrm{dn} / \mathrm{dc}$ value was fixed to $0.72 \mathrm{~mL} / \mathrm{g}$ for PCL ${ }^{61}$ due to the reaction scale and impurities present.

In each case, the NMR spectra of the derived polymers was consistent with previously published spectra for PM, PDC and PCL. ${ }^{19,20,30,59,60}$ The molecular mass and dispersity of purified PM (Table 3) was shown to be very similar to the previously described polymer generated using the same ROP catalyst with chemically-synthesised menthide $\left(\mathrm{M}_{\mathrm{w}} \sim 8.0 \mathrm{kD}\right.$; $\left.\mathrm{Ð}_{\mathrm{M}} \sim 1.2\right) .{ }^{30}$ Therefore, the ROP polymerization of the bio-sourced menthide has successfully generated polymers of similar characteristics as PM from chemically synthesised monomers.

Polymers of bio-derived dihydrocarvide showed a very similar molecular mass and dispersity as PM (Table 3). The only report of ROP using $\left[\mathrm{Mg}(\mathrm{BHT})_{2}(\mathrm{THF})_{2}\right]$ catalyst with dihydrocarvide was co-polymerizations with $\omega$-pentadecalactone. ${ }^{30}$ Control PCL polymers showed similar number average molecular weight but broader dispersity $\left(\bigoplus_{M}=1.79\right)$ than PM and PDC (Table 3) reflective of a faster rate of polymerization. Previous ROP, using a manganese catalyst, gave similar PCL molecular masses under both aerobic and nitrogen environments. ${ }^{60}$ 
The Mark-Houwink plot was generated for the three polymers (Figure S25) showing the influence of lactone substitution on main chain flexibility in line with expectation (PDC $>$ PM $>$ PCL). This opens up great potential in generating de novo bio-plastics with variable properties by combining the strategies of BVMO-derived regio-specific lactone generation with milder ROP-based polymerizations.

Crystal structure of WT and variant CHMO $_{\text {Phi1 }}$. To understand the role of active site residues F249, F280 and F435 in determining the regio-selectivity of CHMO $_{\text {Phil }}$ towards (+)dihydrocarvone, the crystal structures of both WT $(2.4 \AA)$ and variant $(2.5 \AA)$ were determined in complex with $\mathrm{NADP}^{+}$(Figure 1). The structures were solved by molecular replacement using the coordinates of the closed form of CHMO from Rhodococcus sp. HI-31 (90\% sequence identity) as the search model. Our repeated efforts to obtain structures in complex with either $(+)$ dihydrocarvone or the lactone product failed.

Both structures possessed BVMO-like Rossmann fold domains for FAD- and NADPH-binding and a third helical domain flanking the cofactor-binding domains (Figure 1A). Clear electron density is observed for FAD and $\mathrm{NADP}^{+}$in both structures. Unusually for monomeric BVMOs, the structures contained two molecules in the asymmetric unit. Analysis of the dimer interface revealed no significant interactions between the two chains of the WT structure. The interface is significantly altered when compared to the one seen in the dimeric structure of 2-oxo- $\Delta(3)-4,5,5$ trimethylcyclopentenylacetyl-coenzyme A monooxygenase from Pseudomonas putida ATCC $17453 .{ }^{62}$ Size exclusion chromatography showed both the WT and variant eluted from the column corresponding to their respective monomeric molecular weights. In addition, analysis of the assemblies by PISA $^{63}$ gave a Complexation Significance Score (CSS) of zero for both CHMO Phi1 structures excluding any formation of quaternary structure in solution and the observed dimeric arrangements are therefore crystallization artefacts.

The WT CHMOPhi1 structure shows the presence of a well-ordered control loop (residues 489-506), which is implicated in the catalytic mechanism of BVMO enzymes. ${ }^{64}$ This suggests the enzyme is 
in a 'closed' conformation, as it closely resembles previously described $\mathrm{CHMO}_{\text {tight }}{ }^{65}$ and $\mathrm{CHMO}_{\text {closed }}$ structures. ${ }^{66}$ In contrast, the control loop region of the variant $\mathrm{CHMO}_{\text {Phi1 }}$ structure exhibits altered conformation and lack of electron density for residues 496-504. The altered residues (487-495) have significantly moved away from the active site, which resulted in the side chain of W493 now positioned at a distance of $6.4 \AA$ (measured between NE atoms) from WT location. There is also a significant conformational change between the $\mathrm{NADP}^{+}$-binding domains of the two structures (Figure 1B). The movement of the $\mathrm{NADP}^{+}$-binding domains is similar to that observed for the Rhodococcus sp. HI-31 $\mathrm{CHMO}_{\text {open }}$ and $\mathrm{CHMO}_{\text {closed }}$ structures, ${ }^{66}$ suggesting the variant $\mathrm{CHMO}_{\mathrm{Phil}}$ structure is in an 'open' conformation.

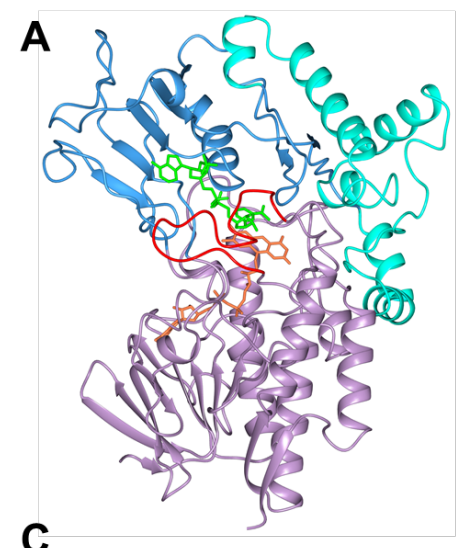

C

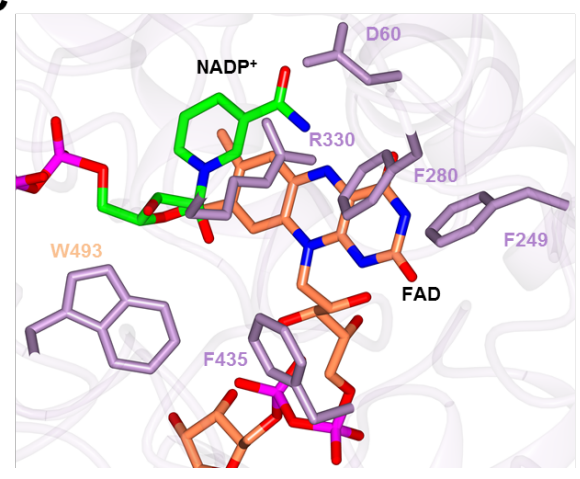

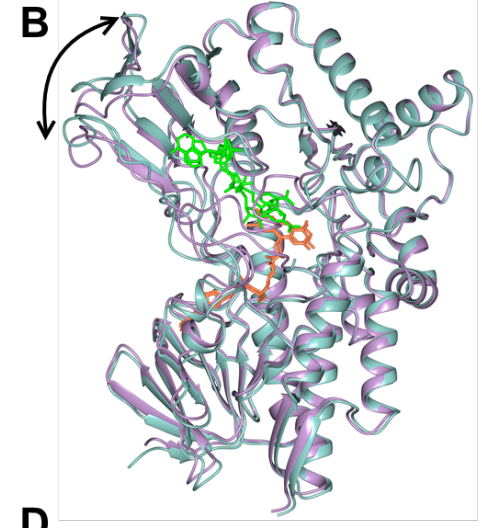

D

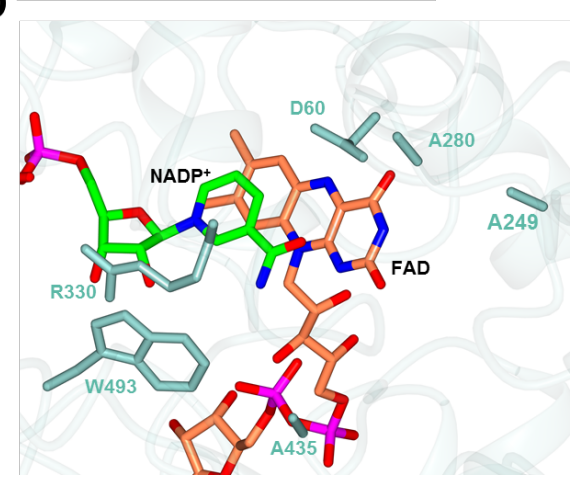

Figure 1. Crystal structures of WT CHMO Phi1 and the F435A, F280A, F249A variant. A) Cartoon representation of $\mathrm{CHMO}_{\text {Phil }}$ WT structure with the $\mathrm{NADP}^{+}$domain is shown in blue, FAD domain in lilac and the helical domain in cyan. The control loop is shown as a red loop. B) Cartoon representation of an overlay of WT (lilac) and variant (aqua) structures of $\mathrm{CHMO}_{\text {Phil }}$. The arrow indicates the movement of $\mathrm{NADP}^{+}$domains when the FAD-domains are anchored. Active site of C) WT and D) variant CHMO Phil 
(chain A) structure showing side chains of key residues as lilac and aqua sticks, respectively. In all panels, the $\mathrm{FAD}$ and $\mathrm{NADP}^{+}$are shown as atom colored sticks with orange and green carbons, respectively.

There are several notable active site differences between the WT and variant structures of $\mathrm{CHMO}_{\mathrm{Phil}}$. In the WT closed structure, the nicotinamide ring of $\mathrm{NADP}^{+}$is positioned almost parallel to the isoalloxazine ring of FAD, with a distance of $2.81 \AA$ between the N7 atom of NADP ${ }^{+}$ and N5 of FAD. The conserved residues R330 and D60 form a salt bridge (Figure 1C), and are involved in the positioning of $\mathrm{NADP}^{+}$and substrate, as noted in prior work. ${ }^{62}$ In the variant structure this interaction is absent, with one conformation of R330 positioned close to W493 (chain A, Figure 1D) and the second between mutated residues A280 and A435 (chain B; Figure 1C-D). Free from the salt bridge, D60 in the variant is pointing inwards into the active site.

Variant mutations F280A and F249A are located close to the FAD and NADP ${ }^{+}$, resulting in the movement of the nicotinamide moiety downwards aligning with the face of the isoalloxazine ring of FAD and losing the interactions with S189 and N193. This change in position in the variant structure is likely facilitated by the displaced control loop, and has resulted in an increase in the distance between the $\mathrm{NADP}^{+} \mathrm{N} 7$ atom and the FAD N5 atom to $6.4 \AA$. There is also a loss of the control loop residue $\mathrm{W} 493 \mathrm{NE}$ to $\mathrm{NADP}^{+} \mathrm{O} 3$ hydrogen bond in the variant structure providing flexibility to the ribose moiety. Additionally, the F435A mutation has resulted in significant rearrangement of the nearby residues from 434 to 438 , which forms the boundary to one side substrate binding pocket. This loop arrangement has caused the N437 side chain in the variant to twist horizontally towards the nicotinamide moiety and form a hydrogen bond.

Two regions near the active site display significant backbone differences when the two structures were superposed. Residues 146-151 and 380-386 are positioned away from the active site in the variant, possibly to accommodate the new location of $\mathrm{NADP}^{+}$. It is worth noting that the observed backbone differences extend beyond the active site and continue to the NADP ${ }^{+}$-binding domain. In addition to D60, R330, N437, W493 and the three mutations discussed above, backbone differences 
have also contributed to the change in the active site area in the variant. In particular, the side chains of L146 and L147 are now located considerably further away from the active site, contributing to the expansion of substrate binding pocket. In summary, the variant $\mathrm{CHMO}_{\text {Phil }}$ structure show that the three mutations have resulted in a significant increase in the overall size of the active site pocket, and changes in the interaction between $\mathrm{NADP}^{+}, \mathrm{FAD}$ and/or protein residues. Computational study of $\mathrm{CHMO}_{\text {Phi1 }}$ regio-selectivity. The switch in regio-selectivity for lactone formation observed between WT and variant $\mathrm{CHMO}_{\text {Phil }}$ suggests a change in the conformation(s) of $(2 R, 5 R)-(+)$-dihydrocarvone bound in the active site. Detailed understanding of the structural and energetic effects of changes to the active site pocket and the interactions between cofactors, protein residues and substrate conformers will be important for the computational design, screening and optimisation of biocatalysts. Here, molecular dynamics simulations and DFT calculations on cluster models have been used to identify important features. The results are described briefly here, with a more in-depth discussion of the computational approaches used and insights gained in the Supporting Information.

BVMOs catalyse the NADPH-dependent oxygen insertion into a carbon-carbon single bond of acyclic and cyclic ketones. ${ }^{67,68}$ The reaction proceeds via a Criegee intermediate (Scheme 2A) The regio-selectivity of the reaction arises because the migrating substituent and the $\mathrm{O}-\mathrm{O}$ bond of the peroxy group need to be anti-periplanar, ${ }^{69}$ which is controlled by the orientation of the substrate within the active site. ${ }^{54}$ The normal or abnormal lactone (Scheme 1) is formed dependent on whether oxygen insertion occurs adjacent to the more highly or less substituted carbon atom, respectively. ${ }^{54}$ 
A)

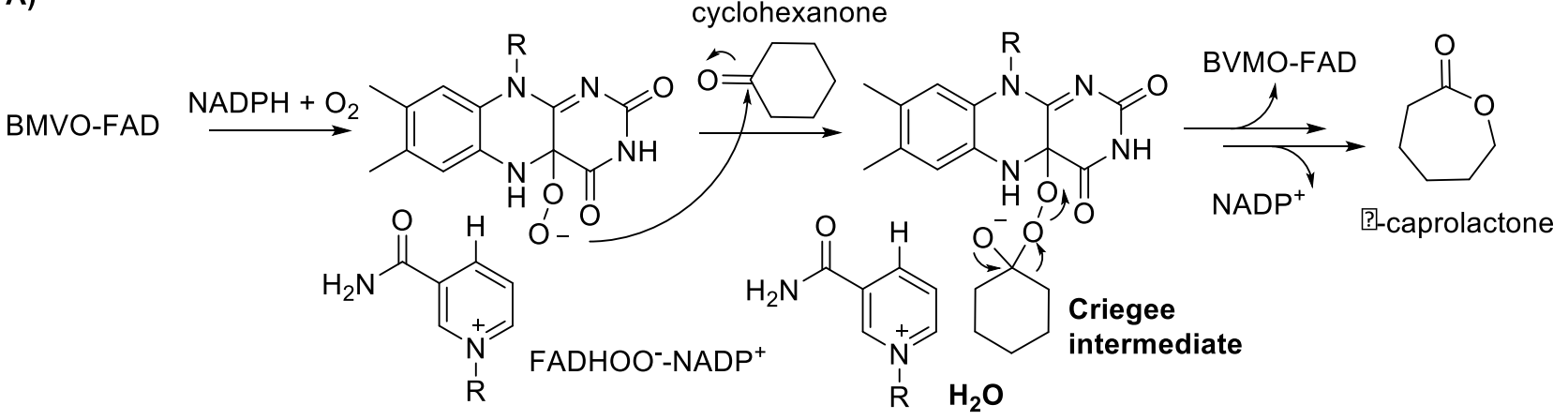

B)
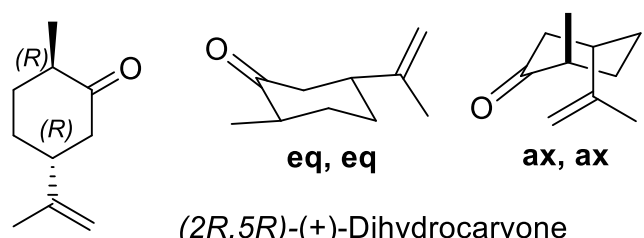

$(2 R, 5 R)-(+)$-Dihydrocarvone

Scheme 2. A) Mechanism of formation of the Criegee intermediates in the reaction between BVMO-FAD, $\mathrm{NADPH}, \mathrm{O}_{2}$ and cyclohexanone. Mechanism is adapted from Yachnin, B.J. et al $(2012)^{70}$ B) Molecular structure and conformations of $(2 R, 5 R)-(+)$-dihydrocarvone.

Detailed conformational studies of cyclohexanones show that the six-membered ring is likely to be most stable in a chair conformation, ${ }^{71}$ with the two substituents placed in either an equatorial, equatorial (eq, eq), or in an axial, axial (ax, ax) arrangement (Scheme 2B). ${ }^{72-77}$ For $\mathrm{CHMO}_{\text {Phi1- }}$ catalysed (+)-dihydrocarvone oxidation, only the $(2 R, 5 R)$ isomer is consumed. For this isomer, the equatorial conformation is slightly more favorable (by $1.8 \mathrm{kcal} / \mathrm{mol}^{-1}$ in the isolated $(2 R, 5 R$ ) isomer at the present level of theory, in agreement with molecular mechanical studies of related cyclohexanone $^{75}$. In the cluster models of the active site considered here (Table 4 below), the energy preference (calculated by DFT) for the equatorial conformer increases in the reactant complex compared to the isolated substrate (by between 3.5 and $8.5 \mathrm{kcal} \mathrm{mol}^{-1}$ ), suggesting that the site is selective.

As the crystallographic data suggested significant differences in the active site on going from WT to variant structures of $\mathrm{CHMO}_{\mathrm{Phi}}$, molecular dynamics (MD) simulations (see Supporting Information for details) were used to identify persistent steric interactions with the active site. Three independent replicas of molecular dynamics simulations were performed using the crystal structures 
of WT and variant $\mathrm{CHMO}_{\mathrm{Phi1}}-\mathrm{NADPH}-\mathrm{FAD}$ without the substrate and the Criegee intermediate in both conformations. For the WT, this showed that the Criegee intermediate in the ax, ax conformation sterically clashes with nearby residues, making it less favorable than the eq, eq conformer. In contrast, both conformations are readily accommodated by the variant structure (see below and further discussion in Supporting Information for further discussion).

Simulations with the WT enzyme showed that the Criegee intermediate in the eq, eq conformation was stable during the $100 \mathrm{~ns}$ of MD simulation in three replicas, and interacted with residues F435, F249, F280 and W493 (Figure 2 and S23a). In contrast, simulations with the Criegee intermediate in the ax, ax conformation showed a switch in conformation to the eq, eq form after $40 \mathrm{~ns}$ in the first replica, $16 \mathrm{~ns}$ and $21 \mathrm{~ns}$ in the second and third, respectively (Figure S23b). Interestingly, when the variant structure was used, both Criegee intermediate conformers were stable during the simulation time (Figure 2 and S23c-d). This may be due to the relatively larger active site cavity and increased flexibility of the control loop, which was seen during simulations of the WT and variant $\mathrm{CHMO}_{\text {Phi1 }}$ without the Criegee intermediate (Figure S22). In particular, accommodation of the ax, ax substrate conformer in the variant protein could be partly due to the movement of residue W493 (control loop residue) away from the active site.

The MD simulations suggest that close contacts with W493 destabilise the ax, ax conformer of the substrate, making the WT selective for the eq, eq conformer and leading to the abnormal product. The mutations of F249A, F280A and F435A make the active site larger and, equally importantly, the control loop considerably more flexible. This suggests that both conformers, eq, eq and ax,ax, need to be considered to determine the balance between a kinetic preference for the normal lactone product and other factors (site selectivity, close contacts) which might favor the abnormal lactone instead. 


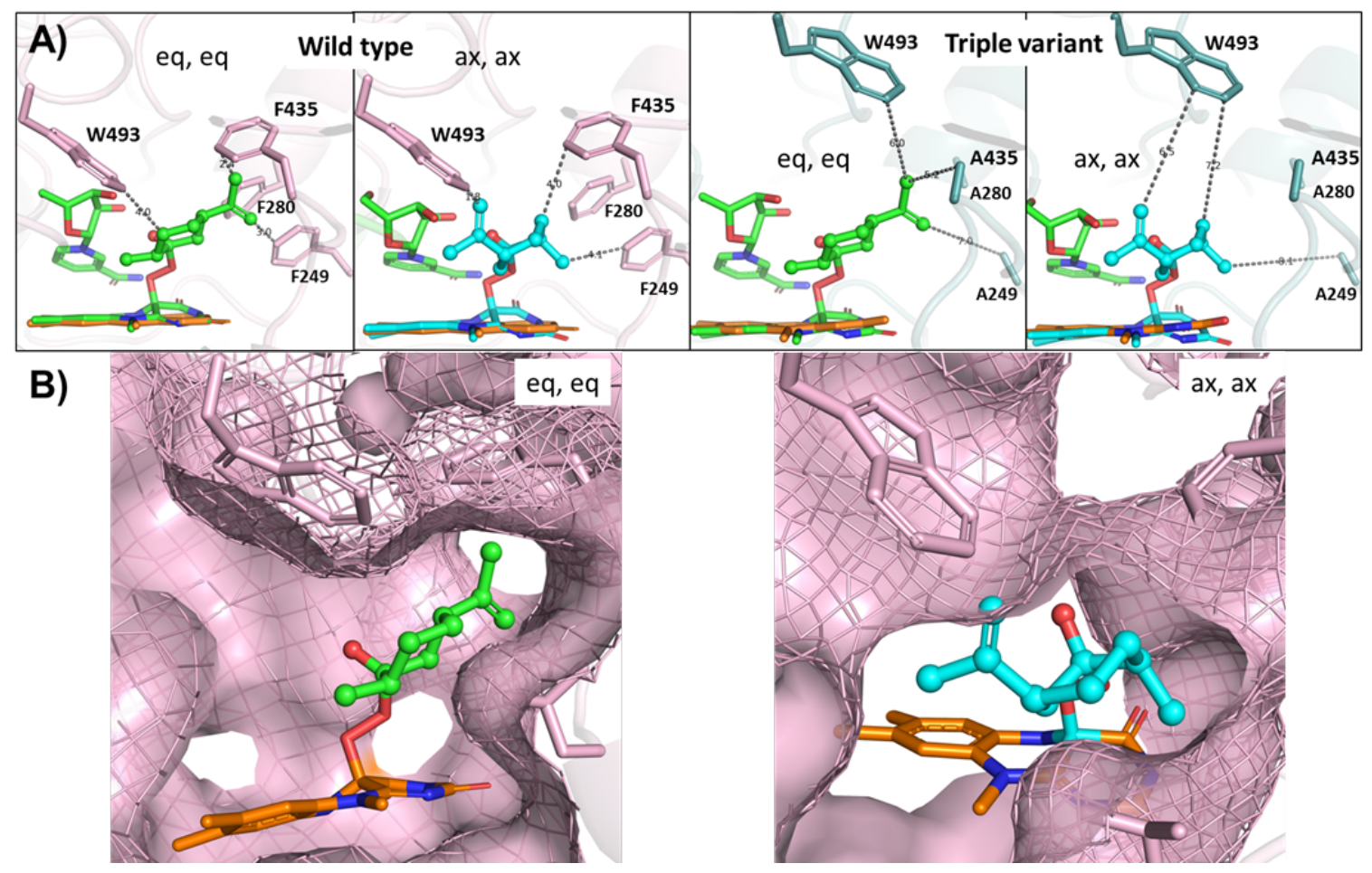

Figure 2. Predictions of the binding of Criegee intermediates in $\mathrm{CHMO}_{\text {Phil }}$. A) Predicted interactions between WT and variant $\mathrm{CHMO}_{\mathrm{Phi}}$ with the Criegee intermediates. The panels are in the same orientation. Criegee intermediate conformers (eq, eq and ax, ax) are shown as atom colored sticks with cyan and green carbons, respectively. Residues of WT and variant $\mathrm{CHMO}_{\text {Phil }}$ are shown as atom colored sticks with pink and orange carbons, respectively. B) Calculated active site/Criegee intermediates in the eq, eq (left) and ax, ax (right) within WT $\mathrm{CHMO}_{\text {Phil }}$ crystal structure. The orientation of the panels is slightly different to facilitate the viewing of the substrate interactions, especially with W493 at the top left of each panel.

DFT calculations on a small 'cluster' model of the active site (M(med), see Supporting Information for full computational details) were used to explore selectivity and reactivity. These calculations were based on a previous mechanistic study of the active site, albeit with different substrates, ${ }^{78}$ and included the $\mathrm{NADP}^{+}$and $\mathrm{FADHOO}^{-}$versions of the cofactors, and R330 with a protonated guanidium which, together with the $\mathrm{NADP}^{+}$ribose hydroxyl groups, allows hydrogen bonds with the substrates. Additional calculations were performed with residue W493 in the crystallographically observed position $\left(\mathrm{M}\left(\mathrm{med}_{-} \mathrm{W}\right)\right.$ or in the absence of R330 (M(med_noR). Geometries of the reactant, Criegee intermediate, migration transition state and product were considered for both $(2 R, 5 R)-(+)$-dihydrocarvone conformations, allowing comparison of the calculated potential energies (Table 4). The analyses did not model the Criegee intermediate 
formation because previous work found this to be energetically more accessible than the migration transition state for a cyclohexanone substrate. ${ }^{78}$

Migration transition states for the regio-isomer of the lactone product in each case (where the migrating group is not antiperiplanar to the O-O peroxide bond) could not be accommodated in the cluster model, producing a range of close contacts that could not be relieved by optimisation within the geometry constraints used (chosen to reproduce the crystallographically-observed residue positions). The eq, eq conformer thus leads only to the abnormal lactone, whereas the ax, ax conformers gives only normal lactone. In contrast, optimization of the product complexes for both lactone products was successful. These active site models do not include any of the residues that were mutated to switch selectivity. Full structural analysis and breakdown of energies as well as a discussion of our approach can be found in the Supporting Information.

Table 4: DFT-calculated potential energies for key stationary points (PWB6K/DZP, $\mathrm{kcal} \mathrm{mol}^{-1}$, see SI for full details, method effects and structural analyses, as well as M(med_noR) data; NL denotes normal lactone, AL abnormal lactone).

\begin{tabular}{llll}
\hline Conformer & eq, eq & $\mathbf{a x , ~} \mathbf{a x}^{\mathbf{a}}$ & $\mathbf{a x , ~ a x ~ o n l y ~}$ \\
\hline M(med_W) & & & \\
\hline Reactant & 0.0 & 3.5 & 0.0 \\
Criegee IM & 6.8 & 11.6 & 8.1 \\
Migration TS & $25.6(\mathrm{AL})$ & $35.3(\mathrm{NL})$ & $31.8(\mathrm{NL})$ \\
Product & $-66.7(\mathrm{AL})$ & $-61.7(\mathrm{NL})$ & $-65.2(\mathrm{NL})$ \\
\hline M(med) & & & \\
\hline Reactant & 0.0 & 8.5 & 0.0 \\
Criegee IM & 8.0 & 9.1 & 0.6 \\
Migration TS & $25.9(\mathrm{AL})$ & $28.4(\mathrm{NL})$ & $19.9(\mathrm{NL})$ \\
Product & $-67.3(\mathrm{AL})$ & $-64.0(\mathrm{NL})$ & $-72.5(\mathrm{NL})$ \\
\hline
\end{tabular}

${ }^{\mathrm{a}}$ Energies relative to eq, eq reactant. ${ }^{\mathrm{b}}$ Energies relative to ax, ax reactant. ${ }^{\mathrm{c}}$ Only one TS could be located for each conformer.

As discussed above and in greater detail in the SI, residue W493 is important for interactions between the substrate and the residues in the active site, and was therefore included in $M\left(m_{-}\right.$_ $)$, which we consider a suitable model for the WT, with $\mathrm{M}(\mathrm{med})$ a possible model for the variant in which this residue moves away from the reacting site. 
Active site models of the WT enzyme containing W493 (M(med_W)) show a clear preference for the eq, eq conformer of the substrate, with a lower barrier to reaction $\left(18.8 \mathrm{vs} 23.7 \mathrm{kcal} \mathrm{moL}^{-1} \mathrm{cf}\right.$. Criegee IM) compared to the ax, ax conformer. The substrate (eq, eq) moves closer to R330 to relieve close contacts with W493, and possibly also F249 and F435 (Figure 2A). This model of the active site captures essential features of the WT enzyme.

In the absence of W493, as could occur in the variant, but retaining R330 in the model (M(med)), site selectivity is actually predicted to be enhanced for the reactant complexes, increasing the preference for the equatorial conformer to $8.5 \mathrm{kcal} \mathrm{mol}^{-1}$. However, the MD simulations above and detailed structural analyses (see Supporting Information) suggest that interactions between the active site and the substrate or product are relatively weak and rely on hydrogen-bonding, making these calculation results noisy and more variable than for the Criegee intermediate in which the substrate is bound more strongly via $\mathrm{O}_{2}$. This is discussed in detail in the Supporting Information. We would encourage caution in over-interpretation of the reactant and product complex energies and their implications for selectivity. There is only a weak calculated preference for the Criegee intermediate of $\mathrm{M}$ (med) with respect to the equatorial conformer (near isoenergetic with ax, ax), with very similar transition state energies for the migration step (equatorial $17.9 \mathrm{kcal} \mathrm{mol}^{-1}$ vs. axial $19.3 \mathrm{kcal} \mathrm{mol}^{-1}$ vs. the related Criegee IMs). However, when barriers to migration compared to the same conformer's reactant complex are considered (considering the eq, eq and ax, ax only columns in Table 4), the axial conformer reacts via a lower barrier and the normal lactone product would be predicted to be produced in this case. This suggests the WT selectivity (modeled by M(med_W)) arises from a clear thermodynamic preference for the eq, eq conformer throughout, leading to the abnormal lactone, while the variant (modeled by $\mathrm{M}(\mathrm{med})$ ) shows an erosion of the preference for the eq, eq conformer in the Criegee intermediate. At this stage, a switch to kinetic control may become possible, favoring the ax, ax conformer in the Criegee intermediate, which could then progress via a lower barrier to reach the migration transition state and produce the normal lactone. 
The mutations were initially identified by Balke et $a l .{ }^{79}$ after docking of the normal lactone product of $(2 R, 5 R)-(+)$-dihydrocarvone (ax, ax substrate conformer) into protein crystal structure geometries of the WT; in later work, a different lactone product, from the reaction of the $(2 S, 5 S)-(+)-$ dihydrocarvone enantiomer, was also considered. ${ }^{57}$ These considerations led the authors to propose the sites for mutation, aimed at opening up the active site to better accommodate the normal lactone, with experimental evaluation used to select the final triple site mutation (F249A, F280A, F435A in the organism used here). As shown in Figure 2A for the relevant Criegee intermediates, these mutations do indeed give rise to a comparatively more open site. In addition, as discussed above, they increase the mobility of other residues, removing the W493 residue from close contacts in the reacting site. These changes could only be detected by MD simulation and crystallographic study of the variant $\mathrm{CHMO}_{\mathrm{Phil}}$ structure as reported here, and will probably reduce the number of unfavorable interactions with substrate conformers. By making the conformers more similar in energy to each other and so reducing inherent site selectivity, the kinetic preference for the $\mathrm{O}$ migrating to the more electron-rich 2-methyl substituent (axial conformer) becomes more important, producing the normal lactone. Such effects are subtle and require consideration of structures and reactivity. Quantifying the energy differences reliably would require extensive sampling (and calculations of binding affinities) rather than a cluster DFT or QM/MM calculation; as discussed in greater detail in the Supporting Information, this lies outside the scope of the present study.

This computational analysis demonstrates the importance of considering key stationary points along the reaction pathway during the computational screening and design process, as the site selectivity for substrate and product alone is not sufficient for explaining the observed product preferences. The reactivity and selectivity changes are subtle, and several effects combine to give the observed outcome. Computational studies aimed at future design should carefully consider the whole range of potentially important and competing effects, of binding and reactivity. These computational models presented here should assist in prediction of selectivity for normal vs. abnormal lactone 
formation by natural and designed CHMOs. This should allow extension to other potential terpene substrates.

\section{CONCLUSIONS}

We present a semi-synthetic approach utilising biocatalysis with non-petroleum feedstocks as a practical route to potentially novel lactone monomers. This approach employs BVMO enzymes which provide control over the enantio- and regio-specificity of monomer production. Further, we have combined experimental and computational approaches to investigate and analyse the causes of the observed selectivity.

This interaction between structural biology, molecular dynamics simulations and quantum chemical models with experimental testing provides a guide for design and thus a roadmap for finding biocatalytic routes for the production of other monomers. We have also demonstrated that menthide and dihydrocarvide can be polymerized using a mild metal-organic catalyst. When combined with the control over isomers of the lactone monomers that biocatalysis enables, this opens up a broader range of polymer physical properties and behaviours for a wide range of applications.

Our platform technology to existing and novel lactone-based polymers combines biocatalyst identification (and potentially future design), adaptation to optimize regio-selective control of monomer formation and environmentally friendly polymer chemistry. Access to existing and novel monomers with improved performance and functionality from feedstocks has the potential to transform polymer production by providing routes to their manufacture, a key element of a nascent circular economy.

\section{ASSOCIATED CONTENT}

\section{Supporting Information}


Additional experimental details, materials used, additional tables and figures, results, GC/MS and NMR analyses, and discussion of additional details of the computational studies (PDF), BVMO xyz coordinates file.

The Supporting Information is available free of charge on the ACS Publications website at DOI:

\section{AUTHOR INFORMATION}

\section{ORCID}

Hanan L. Messiha: 0000-0002-7459-5057; Syed T. Ahmed:@@@; Vijaykumar Karuppiah: @@@; Reynier Suardíaz: 0000-0002-1035-9020; Gabriel Ascue Avalos:@@@; Natalie Fey: 0000-0003-0609-475X; Stephen Yeates:@@@; Helen S. Toogood: 0000-0003-4797-0293; Adrian J. Mulholland:@@@; Nigel S. Scrutton:0000-0002-4182-3500

\section{Author Contributions}

The manuscript was written through contributions of all authors. All authors have given approval to the final version of the manuscript.

\section{Funding Sources}

The UK Catalysis Hub (http://www.ukcatalysishub.co.uk) is kindly thanked for resources and support. Funding was provided by EPSRC (grants EP/K014706/1, EP/K014668/1, EP/K014854/1EP/ K014714/1, EP/M022609/1 and EP/M013219/1).

\section{Notes}

The authors declare no competing financial interest.

\section{ACKNOWLEDGMENTS}

The authors thank Malvern Instruments Ltd, UK for allowing the use of their OMNISEC system to characterize the polymers produced in this study. The authors are grateful to Dr John Morrison (School of Chemistry, University of Manchester) for providing the metal-organic catalyst used in this study. We thank Dr. Colin Levy, Manchester Protein Structure Facility (MPSF), for help with X-ray data collection. We also thank Diamond Light Source (DLS) for access to beamlines 
(proposal number mx12788) and the beamline scientists for their help. We thank Dr Kara Ranaghan and Dr Marc Van der Kamp (University of Bristol) for helpful discussions of the computational study.

\section{REFERENCES}

[1] Gandini, A., and Lacerda, T. M. (2015) From monomers to polymers from renewable resources: Recent advances, Prog Polym Sci 48, 1-39.

[2] Miller, S. A. (2013) Sustainable Polymers: Opportunities for the Next Decade, Acs Macro Lett 2, 550-554.

[3] Musto, P. (2013) Grand challenges in polymer chemistry: energy, environment, health, Front Chem 1,31.

[4] Zhu, Y., Romain, C., and Williams, C. K. (2016) Sustainable polymers from renewable resources, Nature 540, 354-362.

[5] Labet, M., and Thielemans, W. (2009) Synthesis of polycaprolactone: a review, Chem. Soc. Rev. 38, 3484-3504.

[6] Gupta, A. P., and Kumar, V. (2007) New emerging trends in synthetic biodegradable polymers Polylactide: A critique, Eur Polym J 43, 4053-4074.

[7] Shin, J., Martello, M. T., Shrestha, M., Wissinger, J. E., Tolman, W. B., and Hillmyer, M. A. (2011) Pressure-Sensitive Adhesives from Renewable Triblock Copolymers, Macromolecules 44, 87-94.

[8] Wanamaker, C. L., O'Leary, L. E., Lynd, N. A., Hillmyer, M. A., and Tolman, W. B. (2007) Renewable-resource thermoplastic elastomers based on polylactide and polymenthide, Biomacromolecules 8, 3634-3640.

[9] Wanamaker, C. L., Bluemle, M. J., Pitet, L. M., O'Leary, L. E., Tolman, W. B., and Hillmyer, M. A. (2009) Consequences of Polylactide Stereochemistry on the Properties of PolylactidePolymenthide-Polylactide Thermoplastic Elastomers, Biomacromolecules 10, 2904-2911.

[10] Rydz, J., Sikorska, W., Kyulavska, M., and Christova, D. (2015) Polyester-Based (Bio)degradable Polymers as Environmentally Friendly Materials for Sustainable Development, Int J Mol Sci 16, 564-596.

[11] Zhu, K. J., Lin, X. Z., and Yang, S. L. (1990) Preparation, Characterization, and Properties of Polylactide (Pla) Poly(Ethylene Glycol) (Peg) Copolymers - a Potential-Drug Carrier, $J$ Appl Polym Sci 39, 1-9.

[12] Vert, M., Li, S. M., Spenlehauer, G., and Guerin, P. (1992) Bioresorbability and Biocompatibility of Aliphatic Polyesters, J Mater Sci-Mater M 3, 432-446.

[13] Vert, M., Schwarch, G., and Coudane, J. (1995) Present and Future of Pla Polymers, $J$ Macromol Sci Pure A32, 787-796.

[14] Mainil-Varlet, P., Rahn, B., and Gogolewski, S. (1997) Long-term in vivo degradation and bone reaction to various polylactides. 1. One-year results, Biomaterials 18, 257-266.

[15] Gurusamy-Thangavelu, S. A., Emond, S. J., Kulshrestha, A., Hillmyer, M. A., Macosko, C. W., Tolman, W. B., and Hoye, T. R. (2012) Polyurethanes based on renewable polyols from bioderived lactones, Polym Chem-Uk 3, 2941-2948.

[16] Tschan, M. J. L., Brule, E., Haquette, P., and Thomas, C. M. (2012) Synthesis of biodegradable polymers from renewable resources, Polym Chem-Uk 3, 836-851.

[17] Hillmyer, M. A., and Tolman, W. B. (2014) Aliphatic Polyester Block Polymers: Renewable, Degradable, and Sustainable, Accounts Chem Res 47, 2390-2396. 
[18] Chung, H., Yang, J. E., Ha, J. Y., Chae, T. U., Shin, J. H., Gustavsson, M., and Lee, S. Y. (2015) Bio-based production of monomers and polymers by metabolically engineered microorganisms, Curr. Opin. Biotechnol. 36, 73-84.

[19] Zhang, D. H., Hillmyer, M. A., and Tolman, W. B. (2005) Catalytic polymerization of a cyclic ester derived from a "cool" natural precursor, Biomacromolecules 6, 2091-2095.

[20] Lowe, J. R., Martello, M. T., Tolman, W. B., and Hillmyer, M. A. (2011) Functional biorenewable polyesters from carvone-derived lactones, Polym Chem-Uk 2, 702-708.

[21] Ryerson, C. C., Ballou, D. P., and Walsh, C. (1982) Mechanistic studies on cyclohexanone oxygenase, Biochemistry 21, 2644-2655.

[22] Sheng, D., Ballou, D. P., and Massey, V. (2001) Mechanistic studies of cyclohexanone monooxygenase: chemical properties of intermediates involved in catalysis, Biochemistry 40, 11156-11167.

[23] Pazmino, D. E. T., Baas, B. J., Janssen, D. B., and Fraaije, M. W. (2008) Kinetic mechanism of phenylacetone monooxygenase from Thermobifida fusca, Biochemistry 47, 4082-4093.

[24] van Berkel, W. J., Kamerbeek, N. M., and Fraaije, M. W. (2006) Flavoprotein monooxygenases, a diverse class of oxidative biocatalysts, J. Biotechnol. 124, 670-689.

[25] de Gonzalo, G., Mihovilovic, M. D., and Fraaije, M. W. (2010) Recent developments in the application of Baeyer-Villiger monooxygenases as biocatalysts, ChemBioChem 11, 22082231.

[26] Leisch, H., Morley, K., and Lau, P. C. (2011) Baeyer-Villiger monooxygenases: more than just green chemistry, Chem. Rev. 111, 4165-4222.

[27] Balke, K., Kadow, M., Mallin, H., Sass, S., and Bornscheuer, U. T. (2012) Discovery, application and protein engineering of Baeyer-Villiger monooxygenases for organic synthesis, Org. Biomol. Chem. 10,6249-6265.

[28] Alphand, V., and Furstoss, R. (1992) Microbiological Transformations .23. A Surprising Regioselectivity of Microbiological Baeyer-Villiger Oxidations of Menthone and Dihydrocarvone, Tetrahedron-Asymmetr 3, 379-382.

[29] Cernuchova, P., and Mihovilovic, M. D. (2007) Microbial Baeyer-Villiger oxidation of terpenones by recombinant whole-cell biocatalysts - formation of enantiocomplementary regioisomeric lactones, Org. Biomol. Chem. 5, 1715-1719.

[30] Wilson, J. A., Hopkins, S. A., Wright, P. M., and Dove, A. P. (2015) Synthesis and Postpolymerization Modification of One-Pot omega-Pentadecalactone Block-like Copolymers, Biomacromolecules 16, 3191-3200.

[31] Quilter, H. C., Hutchby, M., Davidson, M. G., and Jones, M. D. (2017) Polymerisation of a terpene-derived lactone: a bio-based alternative to $\varepsilon$-caprolactone, Polymer Chemistry 8 , 833-837.

[32] Arbaoui, A., and Redshaw, C. (2010) Metal catalysts for epsilon-caprolactone polymerisation, Polym Chem-Uk 1, 801-826.

[33] O'Keefe, B. J., Hillmyer, M. A., and Tolman, W. B. (2001) Polymerization of lactide and related cyclic esters by discrete metal complexes, J Chem Soc Dalton, 2215-2224.

[34] Wilbon, P. A., Chu, F. X., and Tang, C. B. (2013) Progress in Renewable Polymers from Natural Terpenes, Terpenoids, and Rosin, Macromol Rapid Comm 34, 8-37.

[35] Albertsson, A. C., and Srivastava, R. K. (2008) Recent developments in enzyme-catalyzed ring-opening polymerization, Adv Drug Deliver Rev 60, 1077-1093.

[36] Yang, Y., Yu, Y., Zhang, Y. X., Liu, C. B., Shi, W., and Li, Q. S. (2011) Lipase/esterasecatalyzed ring-opening polymerization: A green polyester synthesis technique, Process Biochem 46, 1900-1908.

[37] Iwaki, H., Wang, S., Grosse, S., Bergeron, H., Nagahashi, A., Lertvorachon, J., Yang, J., Konishi, Y., Hasegawa, Y., and Lau, P. C. (2006) Pseudomonad cyclopentadecanone monooxygenase displaying an uncommon spectrum of Baeyer-Villiger oxidations of cyclic ketones, Appl. Environ. Microbiol. 72, 2707-2720. 
[38] Brzostowicz, P. C., Walters, D. M., Thomas, S. M., Nagarajan, V., and Rouviere, P. E. (2003) mRNA differential display in a microbial enrichment culture: simultaneous identification of three cyclohexanone monooxygenases from three species, Appl. Environ. Microbiol. 69, 334-342.

[39] Vrtis, J. M., White, A. K., Metcalf, W. W., and van der Donk, W. A. (2002) Phosphite dehydrogenase: a versatile cofactor-regeneration enzyme, Angew. Chem., Int. Ed. Engl.41, 3257-3259.

[40] Johannes, T. W., Woodyer, R. D., and Zhao, H. (2007) Efficient regeneration of NADPH using an engineered phosphite dehydrogenase, Biotechnol. Bioeng. 96, 18-26.

[41] Torres Pazmino, D. E., Snajdrova, R., Baas, B. J., Ghobrial, M., Mihovilovic, M. D., and Fraaije, M. W. (2008) Self-sufficient Baeyer-Villiger monooxygenases: effective coenzyme regeneration for biooxygenation by fusion engineering, Angew. Chem., Int. Ed. Engl. 47, 2275-2278.

[42] Pazmino, D. E. T., Riebel, A., de Lange, J., Rudroff, F., Mihovilovic, M. D., and Fraaije, M. W. (2009) Efficient Biooxidations Catalyzed by a New Generation of Self-Sufficient Baeyer-Villiger Monooxygenases, ChemBioChem 10, 2595-2598.

[43] Winter, G., Lobley, C. M., and Prince, S. M. (2013) Decision making in xia2, Acta Crystallogr., Sect. D: Biol. Crystallogr. 69, 1260-1273.

[44] Kabsch, W. (2010) Xds, Acta Crystallogr., Sect. D: Biol. Crystallogr. 66, 125-132.

[45] McCoy, A. J., Grosse-Kunstleve, R. W., Adams, P. D., Winn, M. D., Storoni, L. C., and Read, R. J. (2007) Phaser crystallographic software, J. Appl. Crystallogr. 40, 658-674.

[46] Terwilliger, T. C., Grosse-Kunstleve, R. W., Afonine, P. V., Moriarty, N. W., Zwart, P. H., Hung, L. W., Read, R. J., and Adams, P. D. (2008) Iterative model building, structure refinement and density modification with the PHENIX AutoBuild wizard, Acta Crystallogr., Sect. D: Biol. Crystallogr. 64, 61-69.

[47] Adams, P. D., Afonine, P. V., Bunkoczi, G., Chen, V. B., Davis, I. W., Echols, N., Headd, J. J., Hung, L. W., Kapral, G. J., Grosse-Kunstleve, R. W., McCoy, A. J., Moriarty, N. W., Oeffner, R., Read, R. J., Richardson, D. C., Richardson, J. S., Terwilliger, T. C., and Zwart, P. H. (2010) PHENIX: a comprehensive Python-based system for macromolecular structure solution, Acta Crystallogr D Biol Crystallogr 66, 213-221.

[48] Emsley, P., Lohkamp, B., Scott, W. G., and Cowtan, K. (2010) Features and development of Coot, Acta Crystallogr D Biol Crystallogr 66, 486-501.

[49] Afonine, P. V., Grosse-Kunstleve, R. W., Echols, N., Headd, J. J., Moriarty, N. W., Mustyakimov, M., Terwilliger, T. C., Urzhumtsev, A., Zwart, P. H., and Adams, P. D. (2012) Towards automated crystallographic structure refinement with phenix.refine, Acta Crystallogr D Biol Crystallogr 68, 352-367.

[50] Joosten, R. P., Long, F., Murshudov, G. N., and Perrakis, A. (2014) The PDB_REDO server for macromolecular structure model optimization, IUCrJ 1, 213-220.

[51] Chen, V. B., Arendall, W. B., 3rd, Headd, J. J., Keedy, D. A., Immormino, R. M., Kapral, G. J., Murray, L. W., Richardson, J. S., and Richardson, D. C. (2010) MolProbity: all-atom structure validation for macromolecular crystallography, Acta Crystallogr D Biol Crystallogr 66, 12-21.

[52] Siegbahn, P. E. (2006) The performance of hybrid DFT for mechanisms involving transition metal complexes in enzymes, $J$ Biol Inorg Chem 11, 695-701.

[53] Blomberg, M. R., Borowski, T., Himo, F., Liao, R. Z., and Siegbahn, P. E. (2014) Quantum chemical studies of mechanisms for metalloenzymes, Chem Rev 114, 3601-3658.

[54] Balke, K., Schmidt, S., Genz, M., and Bornscheuer, U. T. (2016) Switching the Regioselectivity of a Cyclohexanone Monooxygenase toward (+)-trans-Dihydrocarvone by Rational Protein Design, ACS Chem. Biol. 11, 38-43.

[55] van der Donk, W. A., and Zhao, H. (2003) Recent developments in pyridine nucleotide regeneration, Curr. Opin. Biotechnol. 14, 421-426. 
[56] Toogood, H. S., Cheallaigh, A. N., Tait, S., Mansell, D. J., Jervis, A., Lygidakis, A., Humphreys, L., Takano, E., Gardiner, J. M., and Scrutton, N. S. (2015) Enzymatic Menthol Production: One-Pot Approach Using Engineered Escherichia coli., ACS Synthetic Biology 4,1112-1123.

[57] Balke, K., Baumgen, M., and Bornscheuer, U. T. (2017) Controlling the Regioselectivity of Baeyer-Villiger Monooxygenases by Mutation of Active-Site Residues, Chembiochem 18, 1627-1638.

[58] Albertsson, A. C., and Varma, I. K. (2003) Recent developments in ring opening polymerization of lactones for biomedical applications, Biomacromolecules 4, 1466-1486.

[59] Shin, J., Lee, Y., Tolman, W. B., and Hillmyer, W. A. (2012) Thermoplastic Elastomers Derived from Menthide and Tulipalin A, Biomacromolecules 13, 3833-3840.

[60] Fang, H. J., Lai, P. S., Chen, J. Y., Hsu, S. C. N., Peng, W. D., Ou, S. W., Lai, Y. C., Chen, Y. J., Chung, H., Chen, Y., Huang, T. C., Wu, B. S., and Chen, H. Y. (2012) epsilonCaprolactone Polymerization under Air by the Biocatalyst: Magnesium 2,6-Di-tert-butyl-4Methylphenoxide, J Polym Sci Pol Chem 50, 2697-2704.

[61] Zhou, X., and Hong, L. Z. (2013) Controlled ring-opening polymerization of cyclic esters with phosphoric acid as catalysts, Colloid Polym Sci 291, 2155-2162.

[62] Leisch, H., Shi, R., Grosse, S., Morley, K., Bergeron, H., Cygler, M., Iwaki, H., Hasegawa, Y., and Lau, P. C. (2012) Cloning, Baeyer-Villiger biooxidations, and structures of the camphor pathway 2-oxo-Delta(3)-4,5,5-trimethylcyclopentenylacetyl-coenzyme A monooxygenase of Pseudomonas putida ATCC 17453, Appl. Environ. Microbiol. 78, 2200-2212.

[63] Krissinel, E., and Henrick, K. (2007) Inference of macromolecular assemblies from crystalline state, J Mol Biol 372, 774-797.

[64] Yachnin, B. J., Lau, P. C., and Berghuis, A. M. (2016) The role of conformational flexibility in Baeyer-Villiger monooxygenase catalysis and structure, Biochim. Biophys. Acta 1864, 16411648.

[65] Yachnin, B. J., McEvoy, M. B., MacCuish, R. J., Morley, K. L., Lau, P. C., and Berghuis, A. M. (2014) Lactone-bound structures of cyclohexanone monooxygenase provide insight into the stereochemistry of catalysis, ACS Chem. Biol. 9, 2843-2851.

[66] Mirza, I. A., Yachnin, B. J., Wang, S., Grosse, S., Bergeron, H., Imura, A., Iwaki, H., Hasegawa, Y., Lau, P. C., and Berghuis, A. M. (2009) Crystal structures of cyclohexanone monooxygenase reveal complex domain movements and a sliding cofactor, $J$ Am Chem Soc $131,8848-8854$.

[67] ten Brink, G. J., Arends, I. W. C. E., and Sheldon, R. A. (2004) The Baeyer-Villiger Reaction: New Developments toward Greener Procedures, Chemical Reviews 104, 41054124.

[68] Krow, G. R. (1993) The Baeyer-Villiger oxidation of ketones and aldehydes, Organic Reactions.

[69] Grein, F., Chen, A. C., Edwards, D., and Crudden, C. M. (2006) Theoretical and Experimental Studies on the Baeyer-Villiger Oxidation of Ketones and the Effect of $\alpha$-Halo Substituents, The Journal of Organic Chemistry 71, 861-872.

[70] Yachnin, B. J., Sprules, T., McEvoy, M. B., Lau, P. C. K., and Berghuis, A. M. (2012) The Substrate-Bound Crystal Structure of a Baeyer-Villiger Monooxygenase Exhibits a Criegeelike Conformation, J. Am. Chem. Soc. 134, 7788-7795.

[71] Rothbächer, H., and Suteu, F. (1974) Konformationseinflüsse auf das chromatographische Verhalten einiger Monoterpenketone, Journal of Chromatography A 100, 236-239.

[72] Allinger, N. L., Allinger, J., and DaRooge, M. A. (1964) Conformational Analysis. XXXVIII. The Conformations of Cyclohexanone Rings, Journal of the American Chemical Society 86, 4061-4067.

[73] Allinger, N. L., Blatter, H. M., Freiberg, L. A., and Karkowski, F. M. (1966) Conformational Analysis. LI. The Conformations of Cyclohexanone Rings in Simple Molecules1-3, Journal of the American Chemical Society 88, 2999-3011. 
[74] Basso, E. A., Kaiser, C., Rittner, R., and Lambert, J. B. (1993) Axial/equatorial proportions for 2-substituted cyclohexanones, The Journal of Organic Chemistry 58, 7865-7869.

[75] Langley, C. H., Lii, J.-H., and Allinger, N. L. (2001) Molecular mechanics calculations on carbonyl compounds. III. Cycloketones, Journal of Computational Chemistry 22, 14511475.

[76] Potts, A. R., and Baer, T. (1997) Conformational enthalpies, $\Delta \mathrm{H}^{\circ}$ [axial/equatorial], of 3- and 4-methylcyclohexanone, Journal of Molecular Structure: THEOCHEM 419, 11-18.

[77] Yoshinaga, F., Tormena, C. F., Freitas, M. P., Rittner, R., and Abraham, R. J. (2002) Conformational analysis of 2-halocyclohexanones: an NMR, theoretical and solvation study, Journal of the Chemical Society, Perkin Transactions 2, 1494-1498.

[78] Polyak, I., Reetz, M. T., and Thiel, W . (2012) Quantum Mechanical/Molecular Mechanical Study on the Mechanism of the Enzymatic Baeyer-Villiger Reaction, Journal of the American Chemical Society 134, 2732-2741.

[79] Balke, K., Schmidt, S., Genz, M., and Bornscheuer, U. T. (2016) Switching the Regioselectivity of a Cyclohexanone Monooxygenase toward (+)-trans-Dihydrocarvone by Rational Protein Design, ACS Chemical Biology 11, 38-43. 